\title{
Survey of practice-related stress among United States and European ophthalmologists
}

\author{
William C. Stewart • Michelle P. Adams • \\ Jeanette A. Stewart $\cdot$ Lindsay A. Nelson
}

Received: 23 February 2011 /Revised: 24 March 2011 / Accepted: 27 March 2011 /Published online: 26 April 2011

(C) Springer-Verlag 2011

Several recent reports have highlighted a high level of stress in practicing physicians, and a call for greater intervention to help doctors cope with their practice responsibilities [1-6]. Practice-related stress may lead to physician 'burnout', family problems, reduced quality of patient care, depression, and professional impairment through illicit drug or alcohol abuse [1, 2, 5-9].

Little is known about practice-related stress among ophthalmologists specifically. However, a recent report by Viviers and associates noted a high level of stress among Quebec ophthalmologists [4]. The authors noted that work overload and organizational deficiencies, combined with little professional recognition, were overburdening ophthalmologists. The authors called for intervention by the provincial authorities to help improve practice conditions [4].

The purpose of this study was to survey the extent, causes and treatment of practice-related stress among United States (US) and European ophthalmologists.

This study was supported clinically by Teleios, Inc., a private foundation. PRN Pharmaceutical Research Network, LLC received no financial support from any other private or government funding source. No authors have proprietary interests to declare. This data has not been presented at a meeting.

The authors have full control of all primary data, and agree to allow Graefe's Archive for Clinical and Experimental Ophthalmology to review data upon request. Clinical Trial registration was not applicable.

W. C. Stewart $(\bowtie) \cdot$ J. A. Stewart

PRN Pharmaceutical Research Network, LLC,

6296 Rivers Avenue, Suite 309,

Charleston, SC 29406, USA

e-mail: info@prnorb.com

M. P. Adams $\cdot$ L. A. Nelson

Charleston Research Company, LLC,

Charleston, SC, USA

\section{Physician selection}

The survey was conducted from the administrative office of PRN Pharmaceutical Research Network, LLC in Charleston, South Carolina, USA between June and August 2010.

The US and European physician lists were compiled from www.yellowpages.com. Names were selected in decreasing order by the most populated cities in the US or by the most populated countries in the European Union until 2,500 names and corresponding e-mail addresses were obtained separately for each continent. Every fifth ophthalmologist was chosen in alphabetical order until 500 names were reached for each continent. It is worthy of note that 100 of the European email addresses were no longer functional.

The survey was developed internally at PRN Pharmaceutical Research Network, LLC by one of the authors (WCS). Questions were based on issues derived from personal discussions by one of the authors (WCS) with ophthalmic colleagues in Europe and the US, as well as recent legal healthcare changes in the US.

All analyses for this paper were two-way, with a significance level set at 0.05 . All analyses were between the results of European and US physicians and were carried out using appropriate statistical tests as required $[10,11]$.

\section{Physician characteristics}

The complete survey is listed on the journal's website at the end of the online version of this manuscript. There were 68 physicians responding in the US out of 500 surveys sent (14\%), and 65 from Europe out of 400 surveys sent (16\%).

There were no significant differences between the characteristics of physicians in the US and Europe in terms of type of ophthalmic practice, age, gender and hours worked per week $(P>0.11)$. However, there was a 
difference in the amount of time taken off work, with Europe having more physicians taking 5-6 weeks of vacation $(P<0.0001)$.

\section{Stress factors}

The extent of practice stress noted by physicians was equal between the two continents, being $6.1 \pm 5.0$ in the US and $5.8 \pm 4.2$ in Europe (range 0-10, $P=0.89$ ). However, factors causing stress differed between continents. Physicians in the US noted 'patient care' as the most common stressrelated factor, whereas both 'patient care' and 'hospital/ clinic administration' were cited in Europe $(P=0.009$, Table 1).

Recent changes in healthcare worsened stress in 48 (71\%) of responding physicians from the US and 52 (80\%) in Europe $(P=0.21)$. The most common causes of stress in Europe were changes in 'hospital and clinic administration' and 'local/national government'. In contrast, in the US, changes in 'financial reimbursement' and 'local/national government' $(P=0.005)$ were most common.

Accordingly, many physicians in the US and Europe noted that the changes in healthcare had caused them to 'change their practice plans' [in $44(65 \%)$ and $39(60 \%)$ respondents respectively $(P=0.73)]$. The most common change in the US was 'an increased size of the practice' whereas in Europe it was 'later retirement'.

\section{Stress alleviation}

Most ophthalmologists indicated they used techniques to alleviate practice-related stress for which the primary tool in both continents was recreational activities (Table 1, $P=$ 0.25 ). As a secondary means to alleviate stress, European physicians most commonly noted 'nothing' or 'recreational activities' and in the US 'recreational' or 'religious activities' $(P=0.058)$.

The mean efficacy of the primary measure to alleviate stress (range $0-10$ ) was $6.8 \pm 2.1$ in the US and $6.7 \pm 2.2$ in Europe $(P=0.83)$. With regard to differences in efficacy of activities, most were similar in perceived efficacy except that religious activity as a primary stress-relieving activity in the US was $8.2 \pm 1.5$, and was statistically better than recreational activities $(6.8 \pm 2.0, P=0.04)$. The secondary measure to alleviate stress was rated essentially as effective as the primary measure $(P=0.78)$.

\section{Medicine as a career}

When asked what advice they would give a medical student considering becoming a physician, there was a borderline difference between continents $(P=0.057$, ) with $51 \%$ in the US versus $28 \%$ in Europe saying 'definitely become a physician', versus $25 \%$ in Europe and $16 \%$ in the US indicating to them to 'choose a different career'.

Table 1 Stress factors

a denotes more than one answer was allowed

\begin{tabular}{lllll}
\hline & $\begin{array}{l}\text { Total } \\
(n=133)\end{array}$ & $\begin{array}{l}\text { United States } \\
(n=68)\end{array}$ & $\begin{array}{l}\text { Europe } \\
(n=65)\end{array}$ & $P$-value \\
\hline What are the practice-related stress-factors? $^{\text {a }}$ & & & & 0.009 \\
None & 5 & 3 & 36 & \\
Patient care & 79 & 43 & 38 \\
Dealing with hospital/clinic administration & 60 & 22 & 26 \\
Dealing with hospital/clinic personnel & 49 & 23 & 16 \\
Dealing with local/national government & 40 & 24 & 11 \\
Dealing with employees & 30 & 19 & 11 \\
Cash flow & 27 & 16 & 5 \\
Legal environment & 25 & 20 & 9 \\
Other & 27 & 18 & 10 \\
What do you do first to alleviate stress? & & & 44 \\
Nothing & 15 & 5 & 4 \\
Recreational activities & 94 & 50 & 3 \\
Mental relaxation techniques & 6 & 2 & \\
Religious activities & 12 & 9 & 2 \\
Indicate religious preference & & & 0.25 \\
Christian & 9 & 7 & 0 \\
Muslim & 1 & 1 & \\
Medical assistance & 1 & 1 & \\
Other & 4 & 1 & \\
\hline
\end{tabular}




\section{Conclusions}

This survey found that many physicians on both continents, feel at least some stress in their practices which was caused most often by patient care responsibilities. However, in Europe perceived stress was caused to an equal extent by hospital/clinic related administrative factors. Causes of patient care related stress are poorly defined, especially among ophthalmologists, but have been described generally among all specialties as resulting from: making difficult diagnoses, threat of litigation, demanding work load, lack of control, and lack of reward [12-14].

Further, most physicians noted that recent changes in healthcare had worsened stress. In the US, changes in local/ national government or financial reimbursement were cited as the most common causes whereas in Europe changes in 'hospital and clinic administration' and 'local/national government' were noted. Governments have long been involved in health care delivery in both continents. At the time of this survey, the popular press had noted that the passage of medical reform in the US in March 2010 would cause many physicians, of all specialties, to reduce or stop their practice. In our survey, approximately half of the ophthalmologists indicated they would change their practice plans. However, the most common reaction from the respondents was to increase the size of their practice.

In Europe, little indication was found, at the time of this survey, in the popular press that indicated pan-continental issues that explained the increased government-related stress $[15,16]$. Nonetheless, such stress might have arisen from various local factors specific to each administrative region in Europe.

On both continents, the most common measure taken to relieve stress (about $70 \%$ ) by ophthalmologists was recreational activities, which was rated approximately 6/10 effective. Stress relief from physical exercise and religious activity has been described before for patients [17]. However, only exercise has been studied in physicians to our knowledge, and was found helpful in at least one report [19]. Interestingly, religious activity, most often of the Christian faith, scored highest of any activity when used primarily to relieve stress, and was more effective statistically than recreational activities. Also of note was that the secondary measure to alleviate stress was rated essentially as effective as the primary measure.

Although European physicians took more vacation than their US colleagues, it did not appear to affect their selfstress ratings, as they were equal to those of the US. However, it is conceivable, with the added stress from administrative sources, that European physicians might have rated their stress higher without the few extra weeks of vacation.

This study suggests that practice-related stress is common in both the US and Europe, and appears associated most strongly with patient care and (in Europe) with hospital/clinic administration. With moderate success, ophthalmologists most commonly use recreational activities to alleviate stress, and in the US they use religious activities secondarily.

Generally, little information is available wth regard to the extent, causes and treatment of ophthalmic practice-related stress, as well as its effects on patient care outcomes and any influence on future health policies. Future research might better define the specific causes of stress, and more specific mechanisms of how it could be relieved through changes in health care administration, law, and government policies, as well as stress-alleviating activities for the physician.

\section{References}

1. Chams H, Mohammadi SF, Moayyeri A (2004) Frequency and assortment of self-report occupational complaints among Iranian ophthalmologists: a preliminary survey. MedGenMed $6: 1$

2. Frasquilho MA (2005) Medicine, doctors, and persons. Understanding stress to prevent burnout. Acta Méd Port 18:433-443

3. Fuss I, Nübling M, Hasselhorn HM, Schwappach D, Rieger MA (2008) Working conditions and Work-Family Conflict in German hospital physicians: psychosocial and organisational predictors and consequences. BMC Public Health 8:353

4. Viviers S, Lachance L, Maranda MF, Ménard C (2008) Burnout, psychological distress, and overwork: the case of Quebec's ophthalmologists. Can J Ophthalmol 43:535-546

5. Von Känel R (2008) The burnout syndrome: a medical perspective. Praxis (Bern 1994) 97:477-487

6. Linzer M, Manwell LB, Williams ES, Bobula JA, Brown RL, Varkey AB, Man B, McMurray JE, Maguire A, Horner-Ibler B, Schwartz MD, MEMO (Minimizing Error, Maximizing Outcome) Investigators (2009) Working conditions in primary care: physician reactions and care quality. Ann Intern Med $151: 28-36$

7. Flaherty JA, Richman JA (1993) Substance use and addiction among medical students, residents, and physicians. Psychiatr Clin North Am 16:189-197

8. Marshall EJ (2008) Doctors' health and fitness to practise: treating addicted doctors. Occup Med (Lond) 58:334-340

9. Schattner P (1998) Stress in general practice. How can GPs cope? Aust Fam Physician 27:993-998

10. Book SA (1978) Essentials of statistics. McGraw-Hill, Inc, New York

11. Moses LE, Emerson JD, Hosseini H (1984) Analyzing data from ordered categories. N Engl J Med 311:442-448

12. Ghosh AK (2004) Dealing with medical uncertainty: a physician's perspective. Minn Med 87:48-51

13. Elango S (2003) Medical negligence suits: risk management. Med J Malays 58:625-631

14. Riley GJ (2004) Understanding the stresses and strains of being a doctor. Med J Aust 181:350-353

15. Arnetz BB (1997) Physicians' view of their work environment and organisation. Psychother Psychosom 66:155-162 
16. Sutinen R, Kivimäki M, Elovainio M, Virtanen M (2002) Organizational fairness and psychological distress in hospital physicians. Scand J Public Health 30:209-215

17. Stewart WC, Sharpe ED, Kristoffersen CJ, Nelson LA, Stewart JA (2011) Association of strength of religious adherence to attitudes regarding glaucoma or ocular hypertension. Ophthalmic Res 45:53-56
18. Hansen AM, Blangsted AK, Hansen EA, Søgaard K, Sjøgaard G (2010) Physical activity, job demand-control, perceived stressenergy, and salivary cortisol in white-collar workers. Int Arch Occup Environ Health 83:143-153

19. Lemaire JB, Wallace JE (2010) Not all coping strategies are created equal: a mixed methods study exploring physicians' self reported coping strategies. BMC Health Serv Res 10:208 